\title{
Aggregation of Sodium Channels Induced by a Postnatally Upregulated Isoform of Agrin
}

\author{
Andrew A. Sharp and John H. Caldwell \\ Department of Cellular and Structural Biology, Department of Physiology, and the Neuroscience Program, University of \\ Colorado Health Sciences Center, Denver, Colorado 80262
}

Agrin is involved in signaling the formation of high concentrations of acetylcholine receptors (AChRs) at the neuromuscular junction (NMJ). There are multiple isoforms of agrin attributable to alternative splicing, and these isoforms are differentially expressed during development and between tissues. The ability to cluster AChRs varies among the agrin isoforms. Sodium channels (NaChs) are also concentrated at the NMJ. We have tested various agrin isoforms for their ability to induce formation of clusters of NaChs. We grew cocultures of dissociated adult rat muscle fibers with chinese hamster ovary $(\mathrm{CHO})$ cells that had been transfected with different isoforms of agrin. Using immunocytochemical techniques, we determined that after $1 \mathrm{~d}$ in culture, $\mathrm{CHO}$ cells synthesizing the neuronally expressed isoform with an eight amino acid insert (Agrin8) were able to form $\mathrm{NaCh}$ clusters at sites of contact between the $\mathrm{CHO}$ cell and muscle cell. Clusters of NaChs could be formed anywhere along a muscle fiber, but more clusters were detected close to the endplate where the endogenous level of $\mathrm{NaChs}$ was higher. None of the other neuronal-specific agrin isoforms was able to cluster NaChs. Because Agrin8 is the only agrin isoform that is upregulated at birth when NaChs begin to cluster at the NMJ, we conclude that Agrin8 expression by motor neurons is a signal for $\mathrm{NaCh}$ clustering at the $\mathrm{NMJ}$ during normal development.

Key words: sodium channel; agrin; neuromuscular junction; synapse development; ion channel aggregation
Synapses are highly organized structures that require complex molecular interactions to be generated and maintained. Many molecules are highly enriched at the synapse [e.g., at the neuromuscular junction (NMJ); sodium channels ( $\mathrm{NaChs),}$ acetylcholine receptors (AChRs), and acetylcholine esterase] (Froehner, 1991). Such specialization is required for proper interneuronal and neuromuscular signaling. Perhaps the best understood molecular pathway of synaptic organization is the involvement of agrin in the clustering of AChRs at the NMJ (for review, see McMahan, 1990; Nastuk and Fallon, 1993; Apel and Merlie, 1995).

Agrin is an extracellular matrix protein that is produced by neurons, muscle, and other tissues (McMahan et al., 1992). It is present in multiple isoforms as a result of alternative splicing at three sites designated $\mathrm{x}, \mathrm{y}$, and $\mathrm{z}$ in rat (Rupp et al., 1991, 1992). Inserts at the $\mathrm{x}$ and $\mathrm{y}$ sites have little or no effect on AChR distribution. There are three neuronal-specific isoforms of agrin (Ruegg et al., 1992; Hoch et al., 1993), which show varying degrees of activity in clustering AChRs (Ferns et al., 1992, 1993; Gesemann et al., 1995); these have 8 and/or 11 amino acid inserts at the $\mathrm{z}$ site (referred to here as Agrin8, Agrin11, or Agrin19). The isoforms are differentially expressed by different tissues and at

\footnotetext{
Received March 22, 1996; revised Aug. 5, 1996; accepted Aug. 12, 1996.

This work was supported by grants from National Institutes of Health (NS 07083 and NS 26505) and the National Science Foundation (IBN-9213199). We thank Drs. J. Campanelli and R. Scheller for the CHO cell lines transfected with the agrin isoforms, Dr. S. R. Levinson for providing the NaCh-specific antibody, and Dr. Bruce Wallace for comments on this manuscript. We thank Drs. A. Kupfer and C. Monks for use of imaging equipment and advice on immunofluorescence.

Correspondence should be addressed to Dr. John H. Caldwell, University of Colorado Health Sciences Center, Department of Cellular and Structural Biology, 4200 East 9th Avenue, B-111, Denver, CO 80262.

Dr. Sharp's present address: Department of Environmental, Population and Organismic Biology, University of Colorado, Boulder, CO 80309-0334.

Copyright (C) 1996 Society for Neuroscience $0270-6474 / 96 / 166775-09 \$ 05.00 / 0$
}

different developmental stages (Hoch et al., 1993). The isoform with no insert (Agrin0) is widely expressed in the nervous system, muscle, and other non-neuronal cells (Hoch et al., 1993; Thomas et al., 1993).

Compared with the clustering of AChRs, little is known about the mechanism of $\mathrm{NaCh}$ accumulation at the NMJ. The density of $\mathrm{NaChs}$ is $\sim 10$-fold higher at the $\mathrm{NMJ}$ than in nonjunctional regions, and this increased density appears $\sim 1$ week after birth (Caldwell and Milton, 1988; Lupa et al., 1993). Lupa and Caldwell (1994) showed that some component of the basal lamina or Schwann cells was sufficient to induce $\mathrm{NaCh}$ clustering in the absence of innervation in regenerating muscle, as has been shown for AChRs in regenerating frog muscle (Burden et al., 1979). However, bath application of Torpedo agrin to cultures of dissociated adult rat muscle fibers did not induce clustering of $\mathrm{NaChs}$ (Lupa and Caldwell, 1991). This result suggests that either agrin alone is not sufficient to signal $\mathrm{NaCh}$ clustering or that a form of agrin other than that present in Torpedo extracts is required.

The goal of this study was to determine whether any of the rat neuronally expressed agrin isoforms are able to initiate $\mathrm{NaCh}$ clustering. We generated cocultures of adult rat muscle fibers and chinese hamster ovary $(\mathrm{CHO})$ cells that had been transfected with cDNAs for various isoforms of rat agrin. Immunofluorescence techniques were used to assay for the presence of agrin-induced $\mathrm{NaCh}$ clusters. Only $\mathrm{CHO}$ cells expressing the Agrin8 construct were able to induce $\mathrm{NaCh}$ clustering. This suggests that the developmentally regulated neuronal expression of Agrin8 is a signal for the induction of $\mathrm{NaCh}$ clustering at the NMJ.

\section{MATERIALS AND METHODS}

Muscle fiber dissociation. Muscle fibers from the rat flexor digitorum brevis (FDB) were prepared as described previously (Bekoff and Betz, 1977; Lupa and Caldwell, 1991). Briefly, FDB muscles were dissected from the hind feet of adult rats. Individual intact muscle fibers were 
dissociated from the muscle by first incubating the muscle in $2 \mathrm{mg} / \mathrm{ml}$ collagenase type B (Boehringer Mannheim, Mannheim, Germany) in DMEM (high glucose, with L-glutamine) (Life Technologies, Gaithersburg, MD) for $2.5 \mathrm{hr}$ at $37^{\circ} \mathrm{C}$ on a rotating wheel or slow shaker. Each muscle was then placed in $2 \mathrm{ml}$ of sterile rat saline containing (in $\mathrm{mm}$ ): $129 \mathrm{NaCl}, 5 \mathrm{KCl}, 2 \mathrm{CaCl}_{2}, 1 \mathrm{MgCl}_{2}, 11$ glucose, $10 \mathrm{Na}_{2}-\mathrm{PIPES}, \mathrm{pH}$ 7.3, and triturated with fire-polished Pasteur pipettes of decreasing size until single, intact fibers were obtained. The suspension was allowed to stand for $5 \mathrm{~min}$ for the muscle fibers to settle. Supernatant $(1.5 \mathrm{ml})$ was then removed.

CHO cells. CHO cells were obtained from Drs. J. Campanelli and R. Scheller (Stanford University). In addition to wild-type CHO cells, cell lines transfected with full-length cDNAs for four rat agrin isoforms (Agrin0, Agrin8, Agrin11, and Agrin19) were used. These cell lines have been characterized previously (Campanelli et al., 1991; Ferns et al., 1992). The agrin constructs included inserts of 12 amino acids at the $\mathrm{x}$ site and 4 amino acids at the $y$ site. In addition to the cDNA for agrin, the plasmid transfected into $\mathrm{CHO}$ cells contained an insert coding for neomycin resistance (cells not containing the plasmid are killed by the neomycin analog, geneticin). Before coculturing with the FDB fibers, the transfected CHO cells were maintained in DMEM containing $200 \mu \mathrm{g} / \mathrm{ml}$ geneticin (Life Technologies), 10\% FBS (Gemini Bioproducts, Calabasas, CA) and $1 \%$ pen/strep (Life Technologies) at $37^{\circ} \mathrm{C}$ and $5 \% \mathrm{CO}_{2}$. After three passages, the cells were discarded and fresh cultures were begun from frozen stocks (prepared from the original frozen stock provided by Drs. Campanelli and Scheller). This reduced the potential for the loss of the agrin construct.

Substrate for cultures. Glass coverslips were coated with Matrigel (Collaborative Biomedical Products, Bedford, MA) immediately before the addition of cells. A Corning (Corning, NY) coverslip (22 mm square, no. $1)$, dipped in ethanol to sterilize and allowed to dry, was placed into each well of a six-well culture plate. Matrigel $(150 \mu \mathrm{l} ; 0.5 \mathrm{mg} / \mathrm{ml}$ in $0.1 \mathrm{M} \mathrm{PBS})$ was then spread on the coverslips. Coverslips were allowed to stand for 1 $\mathrm{hr}$ at room temperature, and the excess Matrigel was then removed. Cells were added to the coverslips within $15 \mathrm{~min}$.

Cocultures of FDB fibers and $\mathrm{CHO}$ cells. When the $\mathrm{CHO}$ cell cultures had reached confluence, they were rinsed with Dulbecco's PBS and trypsinized for $3 \mathrm{~min}$ (0.25\% trypsin, $\mathrm{Ca}^{2+}$ - and $\mathrm{Mg}^{2+}$-free) (Life Technologies). DMEM containing $10 \% \mathrm{FBS}$ was added. The cells were pelleted and resuspended in rat saline. Approximately $10^{5}$ cells in $50 \mu \mathrm{l}$ of saline were added to the muscle fibers from one FDB muscle. The muscle fibers and $\mathrm{CHO}$ cells were mixed with gentle trituration and divided between six coated coverslips ( $\sim 90 \mu$ l per coverslip). The coverslips were placed in a $37^{\circ} \mathrm{C}, 5 \% \mathrm{CO}_{2}$ incubator for 3-4 hr before culture medium (DMEM with $2.5 \%$ FBS, $5 \%$ horse serum (Life Technologies) and $1 \%$ pen/strep) was added. Cultures were then returned to the incubator for 1-2 d before processing for immunocytochemistry.

Antibodies and biotinylation. NaChs were detected with a rabbit polyclonal antibody [provided by Dr. S. R. Levinson, University of Colorado Health Sciences Center (UCHSC) and available from Upstate Biotechnology, Lake Placid, NY], which recognizes an intracellular epitope that is common to many $\mathrm{NaCh}$ subtypes. Characterization and properties of this antibody are described in Dugandzija-Novakovic et al. (1995). This was followed by a Cy3-conjugated donkey anti-rabbit IgG secondary antibody (Jackson ImmunoResearch Laboratories, West Grove, PA).

Agrin expression in the CHO cells was detected using a mouse monoclonal antibody that recognizes a region near the second epidermal growth factor (EGF)-like domain and binds to all agrin isoforms (Hoch et al., 1994) (catalog \#AGR-530, StressGen, Victoria, BC, Canada). In preliminary experiments, we used a mouse monoclonal that recognizes agrin with any insert at the $\mathrm{z}$ position, with similar results for Agrin8 clustering (catalog \#AGR-520) (StressGen). This was followed by a biotin-SP-conjugated donkey anti-mouse IgG secondary antibody and finally fluorescein-conjugated streptavidin (both from Jackson).

Detection of wild-type $\mathrm{CHO}$ cells was achieved by biotinylating them before trypsin treatment. Cultures were rinsed with Dulbecco's PBS and then reacted for $1 \mathrm{hr}$ at room temperature with $1 \mathrm{mg} / \mathrm{ml}$ biotinyl- $\epsilon-$ aminocaproic acid $N$-hydroxysuccinimide ester (biotin-LC-NHS) (Pierce, Rockford, IL) in Dulbecco's PBS. The reaction was quenched with a 10 -fold dilution in DMEM containing $10 \%$ FBS. Fluoresceinconjugated streptavidin was used for final visualization.

AChRs were detected using biotinylated $\alpha$-bungarotoxin prepared as follows: biotin-LC-NHS $(0.5 \mathrm{mg})$ was dissolved in dimethylformamide ( 9 $\mu \mathrm{l})$. Biotin-LC-NHS $(1 \mu \mathrm{l}), \alpha$-bungarotoxin $(0.1 \mathrm{mg})$ (Sigma, ST. Louis, MO), and $\mathrm{NaHCO}_{3}(10 \mu \mathrm{l}, 0.1 \mathrm{M}, \mathrm{pH} 8.3)$ were mixed and incubated at room temperature for $1 \mathrm{hr}$. The reaction was stopped by adding $1 \mu \mathrm{l}$ glycine $(0.1 \mathrm{M})$. Fluorescein-conjugated streptavidin was used to visualize the biotin-labeled bungarotoxin.

Immunocytochemistry. After 1-2 d in culture, coverslips were removed from the incubator, rinsed three times ( 5 min each) in PBS, and fixed in $4 \%$ paraformaldehyde for $10 \mathrm{~min}$. Three PBS rinses were used between each subsequent treatment. Cells were permeabilized with $0.5 \%$ Triton X-100 (Sigma) in PBS. Nonspecific binding was blocked using $15 \%$ goat serum (Sigma) in PBS for $30 \mathrm{~min}$. Primary antibodies and/or $\alpha$-bungarotoxin were then applied overnight at room temperature diluted in $15 \%$ goat serum as follows: anti-NaCh, 1:100; anti-Agrin, 1:1000; $\alpha$-bungarotoxin, $1: 10^{5}$. Secondary antibodies were also diluted in $15 \%$ goat serum and were applied for $1 \mathrm{hr}$ at the following dilutions: Cy3conjugated donkey anti-rabbit, 1:600; biotin-conjugated donkey antimouse, 1:200. Finally, fluorescein-conjugated streptavidin was added for $1 \mathrm{hr}(1: 600$ in 15\% goat serum). Coverslips were mounted in photobleach protective medium (Vectashield, Vector Laboratories, Burlingame, CA) and sealed with fingernail polish.

Slides were observed on a Nikon Optiphot-2 fluorescence microscope. Digital images were collected using a Zeiss Axiophot fluorescence microscope ( $40 \times$ PlanApo objective, 1.3 numerical aperture) equipped with a cooled CCD camera (MCD 1000, SpectraSource Instruments, Westlake, CA). Fluorescence resulting from emission outside the plane of focus was partially removed using a no-neighbor deconvolution (software written by Drs. C. Monks and A. Kupfer, National Jewish Center and UCHSC). Final image processing was performed using the Corel Graphics software package (Ottawa, Canada). The images were pseudocolored for illustration (see Fig. 3) with the colors reversed (NaCh, green; AChR, red). Linearity was maintained in all transformations.

Quantitation of clustering. For contacts between CHO cells and muscle fibers to be scored for agrin-induced clusters of NaChs, several criteria had to be met. First, a CHO cell had to be clearly in contact with a healthy muscle fiber, and the muscle fiber had to be isolated (bundles of partially dissociated fibers were ignored). Second, the $\mathrm{CHO}$ cell had to express agrin (or be biotinylated in the case of wild-type cells). Third, the endogenous $\mathrm{NaCh}$ signal of the $\mathrm{CHO}$ cell (which was primarily intracellular) had to be separable from the muscle fiber membrane; this meant that it had to be possible by changing the focal plane or by having the cells side-by-side to attribute the signal to one cell or the other. For a contact to be scored as having agrin-induced clustering, the muscle fiber membrane adjacent to the $\mathrm{CHO}$ cell had to show greater fluorescence than the area adjacent to the contact. The signal at the majority of these clusters was scored by visual inspection; for six clusters the increased signal over background was quantitated by digitizing the image and comparing the intensity at the area of contact with adjacent regions of the cell using SigmaScan software (Jandel Scientific, San Rafael, CA), and the relative increase in intensity varied from two- to fivefold.

\section{RESULTS}

\section{NaCh labeling of muscle fibers}

In selecting our assay system, we wished to use a tissue that would maximize levels of endogenous $\mathrm{NaChs}$ available for clustering. We chose to culture adult muscle fibers dissociated from the rat FDB rather than embryonic myotubes, because adult muscle fibers have an extrajunctional sodium current density of $\sim 10 \mathrm{~mA} / \mathrm{cm}^{2}$ (Caldwell and Milton, 1988; Lupa et al., 1993), which is $\sim 10$ times that in embryonic myotubes (R. Milton and J. Caldwell, unpublished observations). Unlike AChRs, $\mathrm{NaCh}$ density changes very little after denervation (Lupa et al., 1995); therefore, we did not denervate the muscles before dissociation.

In previous studies, $\mathrm{NaCh}$ density and distribution was determined primarily with the loose patch voltage clamp technique. In the experiments reported here, we expected there to be changes in channel density at the sites of contact between the agrinexpressing $\mathrm{CHO}$ cells and the muscle fibers, a region difficult or inaccessible for patch clamping. Consequently, we chose to use an anti-NaCh antibody to determine $\mathrm{NaCh}$ distribution. It was possible with the antibody to visualize $\mathrm{NaChs}$ at the endplate of dissociated muscle fibers as well as in the perijunctional membrane of the muscle fiber (Fig. 1). Figure $1 A 1$ shows staining for 

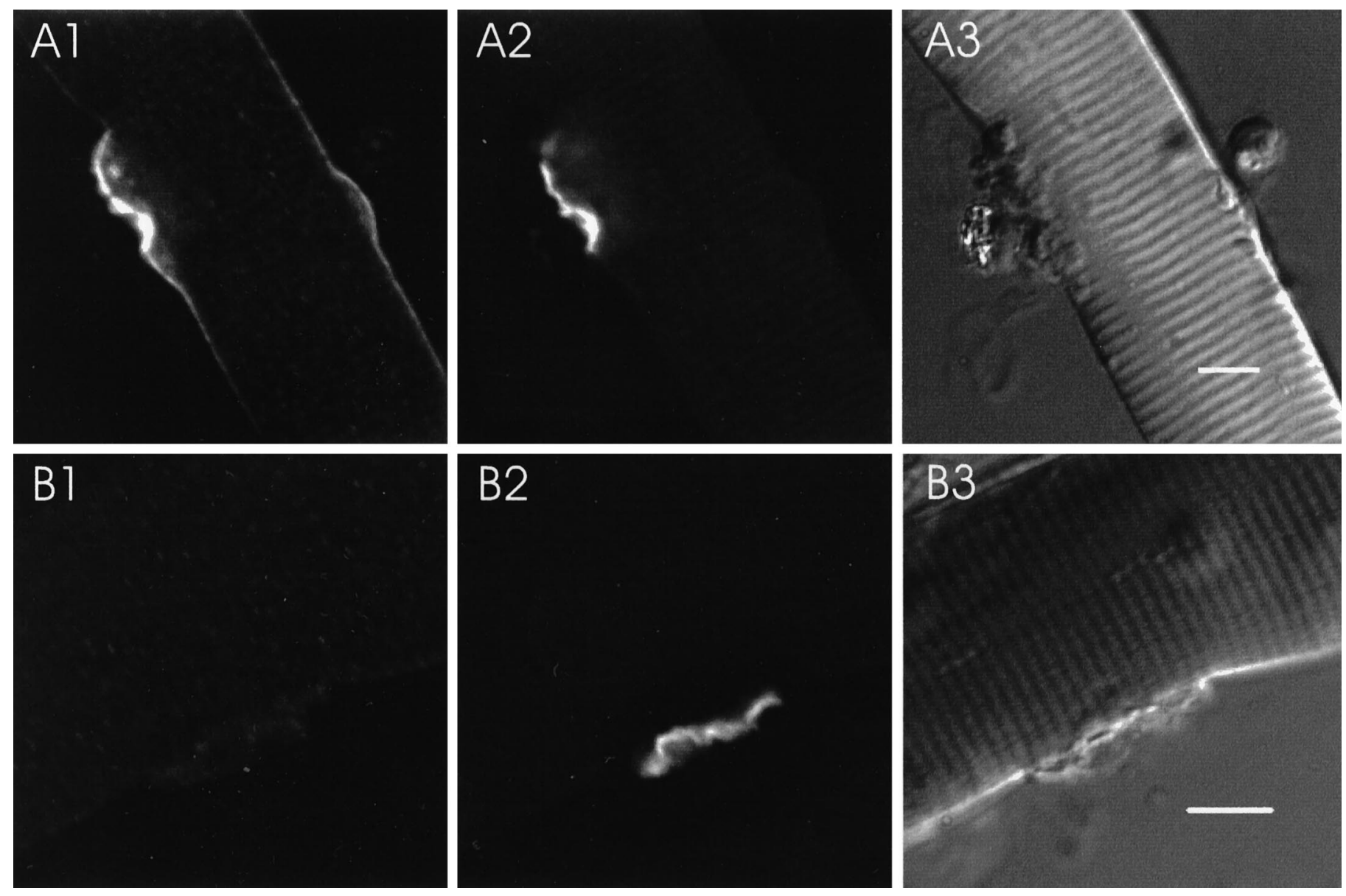

Figure 1. $A, \mathrm{NaCh}$ and $\mathrm{AChR}$ expression on a dissociated FDB muscle fiber ( $A 1-A 3$ are identical fields of view). The fiber was fixed 4 hr after dissociation. $A 1, \mathrm{NaCh}$ labeling. Notice the bright staining of the endplate on the left edge of the fiber and the perijunctional staining on both sides of the muscle fiber. A myonucleus forms a bulge on the right side of the fiber. $A 2$, AChRs labeled with $\alpha$-bungarotoxin. Unlike the NaChs in $A 1$, the AChRs are restricted to the endplate. $A 3$, Nomarski image. $B$, Anti-NaCh antibody control ( $B 1-B 3$ are identical fields of view). Before addition to the muscle fibers, the antibody was incubated for $8 \mathrm{hr}$ at $4^{\circ} \mathrm{C}$ with the peptide against which it was generated. B1, Blocked-antibody labeling. Preincubation abolished labeling of $\mathrm{NaChs}$ in muscle. B2, AChR labeling with $\alpha$-bungarotoxin. B3, Nomarski image. Scale bar, $10 \mu \mathrm{m}$.

$\mathrm{NaChs}$ on a muscle fiber that was fixed $4 \mathrm{hr}$ after dissociation. $\mathrm{NaCh}$ labeling was highest at the endplate (left edge of the fiber), which was identified by AChR labeling with $\alpha$-bungarotoxin (Fig. $1 A 2$ ), and labeling of the perijunctional membrane on both edges of the fiber was also evident. The highest $\mathrm{NaCh}$ signal on the fiber always coincided with the AChR labeling; this allowed us to identify the endplate by $\mathrm{NaCh}$ labeling alone. Preincubation of the anti-NaCh antibody with the peptide to which it was generated $(0.1 \mathrm{mg} / \mathrm{ml})$ blocked labeling of the endplate region (Fig. $1 B)$, indicating that labeling was specific.

$\mathrm{NaCh}$ labeling fell to background levels within $20-80 \mu \mathrm{m}$ of the endplate. This corresponds to a decrease in sodium current density from $100 \mathrm{~mA} / \mathrm{cm}^{2}$ to $20 \mathrm{~mA} / \mathrm{cm}^{2}$, as measured with the loose-patch technique (Caldwell and Milton, 1988; Lupa et al., 1993). If we assume that $1 \mathrm{~mA} / \mathrm{cm}^{2}$ corresponds to $20 \mathrm{NaChs} / \mu \mathrm{m}^{2}$ (see Caldwell et al., 1986), this comparison implies that we can detect $\mathrm{NaChs}$ with the antibody at a density of $\sim 400 \mathrm{NaChs} / \mu \mathrm{m}^{2}$.

$\mathrm{NaCh}$ labeling of the endplate region remained high for $2 \mathrm{~d}$ in culture (the longest time used in these experiments). After $3 \mathrm{~d}$ in culture, labeling of the endplate started to decrease significantly (data not shown). This has also been observed with the loosepatch technique (Lupa and Caldwell, 1991). Identification of the endplate allowed us to determine whether the frequency of $\mathrm{NaCh}$ clusters varied with distance from the endplate.

\section{Agrin and $\mathrm{NaCh}$ expression in $\mathrm{CHO}$ cells}

We used $\mathrm{CHO}$ cell lines that had been transfected previously with various isoforms of agrin (Campanelli et al., 1991; Ferns et al., 1992). These cells are known to express agrin both on the cell surface and intracellularly. Figure $2 C 2$ shows labeling of Agrin8transfected $\mathrm{CHO}$ cells with an antibody that recognizes all isoforms of agrin. By changing the focal plane, labeling could be seen both on the surface of the cells as well as in the cytoplasm. Agrin labeling was not uniform either within a given cell or between different cells. Exclusion of the primary antibody resulted in almost no labeling by the secondary antibody (Fig. 2A2,B2). Agrin labeling of $\mathrm{CHO}$ cells transfected with the other isoforms (Agrin0, Agrin11, and Agrin19) yielded similar results. Wild-type cells showed no labeling by the anti-agrin antibody (data not shown).

CHO cells express NaChs (Lalik et al., 1993) at a level that is detected with anti-NaCh antibodies (Fig. 2C1). Treatment with blocked antibody (preincubated with a large molar excess of the antigenic peptide) also revealed a detectable but lower level of staining (Fig. 2B1); this weak staining was completely abolished if secondary antibody was used alone (Fig. 2A1). Thus, anti-NaCh antibodies bind both specifically and nonspecifically to $\mathrm{CHO}$ cells. $\mathrm{NaCh}$ labeling of the $\mathrm{CHO}$ cells was similar for wild-type and for each of the transfected cell lines. 

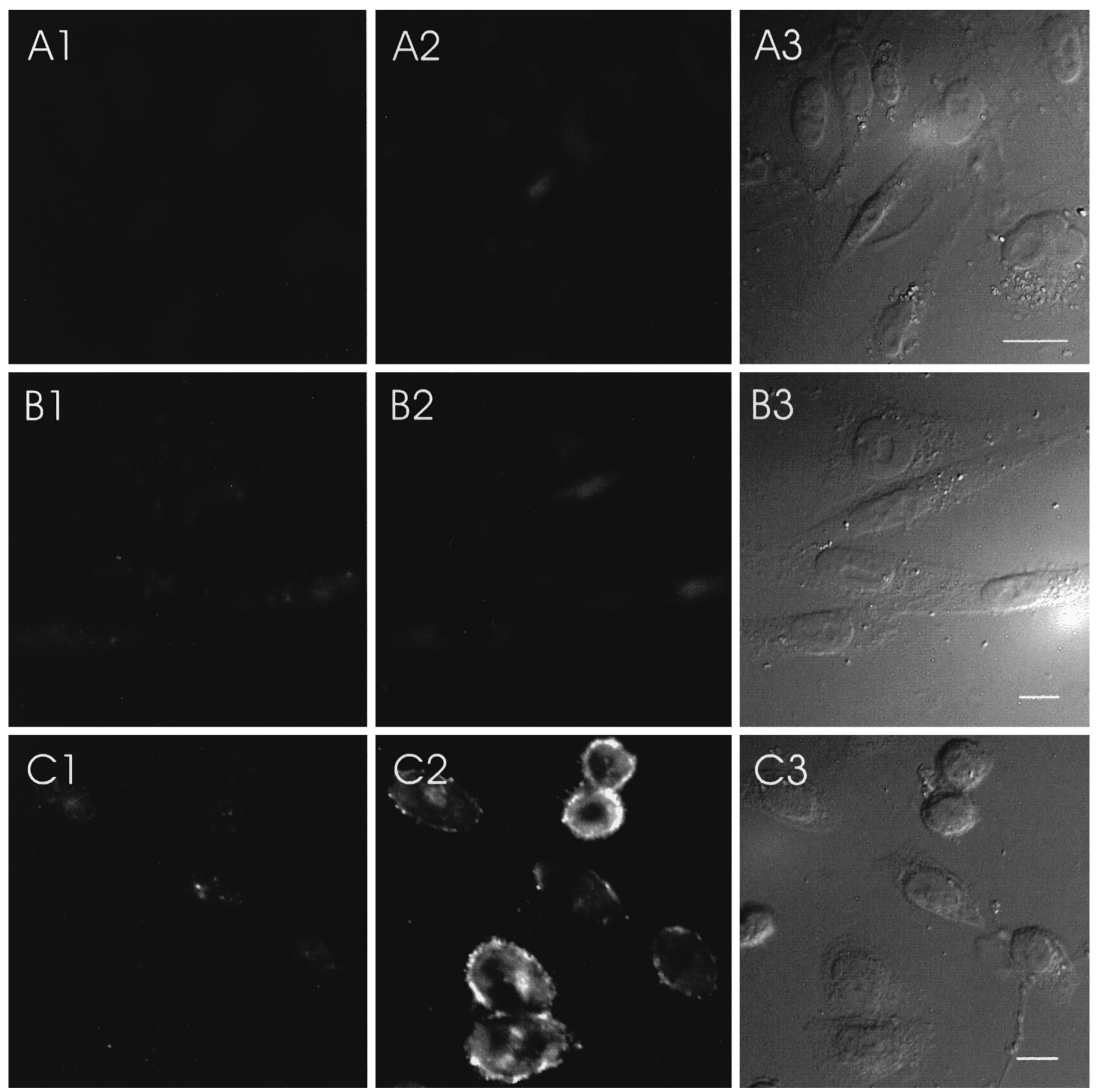

Figure 2. $\mathrm{NaCh}$ and agrin labeling of Agrin8-transfected $\mathrm{CHO}$ cells after $1 \mathrm{~d}$ of culture on Matrigel-coated coverslips. $A$, CHO cell labeling with secondary antibodies alone. Fluorescence when anti-NaCh $(A 1)$ and anti-agrin $(A 2)$ antibodies were omitted. $A 3$, Nomarski image. $B 1, \mathrm{CHO}$ cell labeling with "blocked" anti-NaCh antibody. Notice that there is some non-NaCh labeling of the CHO cells. B2, Weak, diffuse labeling when primary antibody to agrin (same protocol as $A 2$ ) was omitted. B3, Nomarski image. $C 1, \mathrm{NaCh}$ labeling of $\mathrm{CHO}$ cells. This signal is attributable both to a low level of endogenous $\mathrm{NaCh}$ expression in some $\mathrm{CHO}$ cells and to nonspecific labeling by the anti-NaCh antibody (see B1). $\mathrm{C} 2$, Agrin labeling of CHO cells. Notice that expression of agrin is heterogeneous between and within cells. $C 3$, Nomarski image. Scale bars: $A, 20 \mu \mathrm{m} ; B, C, 10 \mu \mathrm{m}$.

\section{Clustering of NaChs by transfected $\mathrm{CHO}$ cells}

Dissociated FDB muscle fibers and $\mathrm{CHO}$ cells were plated at densities that resulted in only a few contacts between $\mathrm{CHO}$ cells and each muscle fiber. The cultures were fixed after either 1 or $2 \mathrm{~d}$ in culture and double-labeled for $\mathrm{NaChs}$ and agrin. The results were the same for the 1 and $2 \mathrm{~d}$ cultures. It was necessary to label the cultures with the anti-agrin antibody, not only to determine whether $\mathrm{CHO}$ cells contacting muscle fibers expressed agrin (see above) but also to distinguish $\mathrm{CHO}$ cells from other cells that originated from the muscle dissociation. To distinguish wild-type $\mathrm{CHO}$ cells from other cell types, $\mathrm{CHO}$ cells were biotinylated before mixing them with muscle fibers; these wild-type cells were visualized with FITC-conjugated streptavidin.

Agrin8-expressing $\mathrm{CHO}$ cells were able to induce clusters of $\mathrm{NaChs}$ on muscle fibers (Fig. 3) after $1 \mathrm{~d}$ in culture (the shortest time we tested). Figure $3 A 1$ shows $\mathrm{NaCh}$ labeling of two muscle 
fibers lying next to each other. Each endplate is indicated by an asterisk. The arrows indicate four clusters of $\mathrm{NaChs}$ induced by two Agrin8-expressing $\mathrm{CHO}$ cells lying between and contacting the fibers. Notice that the $\mathrm{CHO}$ cell membrane not in contact with the muscle fiber has a $\mathrm{NaCh}$ signal below that of the nonjunctional muscle fiber membrane. Figure $3 A 2$ shows agrin labeling of the same field. Endogenous expression of agrin by the muscle fiber does not generate an appreciable signal; this is probably attributable to the removal of the basal lamina by the enzymatic dissociation (Betz and Sakmann, 1973). Only one of the two CHO cells in the figure appeared heavily labeled for agrin in this focal plane. The other $\mathrm{CHO}$ cell was clearly labeled by the agrin antibody in another focal plane (data not shown). Figure $3 B$ shows another example of an Agrin8-transfected cell that has induced $\mathrm{NaCh}$ clusters on two muscle fibers. Notice in the composite images of Figure 3, $A 3$ and $B 3$, that the increase in $\mathrm{NaCh}$ labeling occurs at the contact with the $\mathrm{CHO}$ cells.

Although $\mathrm{CHO}$ cells labeled only weakly with the anti-NaCh antibody (and $\mathrm{NaCh}$ labeling of $\mathrm{CHO}$ cells was primarily intracellular rather than membrane-associated) (Fig. 2C1), we were concerned that the superposition of the weak signal from the $\mathrm{CHO}$ cell with that of the muscle fiber membrane could make it appear that there was an increase in $\mathrm{NaCh}$ concentration at that point. For that reason, only contacts where muscle fiber labeling and $\mathrm{CHO}$ cell labeling could be distinguished were considered as candidates for clustering. To exclude any contribution to the $\mathrm{NaCh}$ signal from labeling of the $\mathrm{CHO}$ cells, most contacts that could be analyzed occurred at the side of muscle fibers. All of the contacts illustrated in Figure 3 were on the side of fibers except Figure $3 C$, which shows an example in which an Agrin8-expressing $\mathrm{CHO}$ cell had contacted the upper surface of a muscle fiber (see Fig. 3C4). In most cases of this latter type, it was not possible to determine whether there was $\mathrm{NaCh}$ clustering in the muscle membrane at the contact site, because the intracellular labeling of the $\mathrm{CHO}$ cell contributed to the signal. However, in this case, the labeling occurred at thin, veil-like $\mathrm{CHO}$ cell membrane contacts, and the intensity of labeling exceeded that in any isolated $\mathrm{CHO}$ cell. We found that approximately one-third (39\%) of the contacts that could be analyzed between Agrin8-expressing $\mathrm{CHO}$ cells and muscle fibers resulted in $\mathrm{NaCh}$ clustering ( 70 of 181 contacts); 154 of 335 contacts $(46 \%)$ were not scorable. This is similar to the percentage of contacts between transfected $\mathrm{CHO}$ cells and rat myotubes that produced AChR clusters (10-50\%) (Campanelli et al., 1991). Because the muscles used in the present experiments were not predenervated, AChR clusters were not expected and, thus, we did not test whether $\mathrm{NaCh}$ clusters coincided with AChR clusters. No spontaneous clustering of $\mathrm{NaChs}$ was observed under any of our culture conditions (with or without $\mathrm{CHO}$ cells). Because clusters were only observed at contact sites, we also conclude that $\mathrm{CHO}$ cells do not induce stable clusters and subsequently migrate away during the time course of these experiments.

One unexpected finding was that $\mathrm{NaCh}$ clustering did not always occur where Agrin8 expression was highest. For example, in Figure $3 C 3$ the intense $\mathrm{NaCh}$ labeling was not co-localized with the maximal agrin labeling. The $\mathrm{NaCh}$ labeling was associated with the contact of the veil-like area of the $\mathrm{CHO}$ cell (see Fig. 3C4). Explanations for this incongruence include the possibility that much of the agrin signal is intracellular, that the density of agrin on the $\mathrm{CHO}$ cells exceeds that required for $\mathrm{NaCh}$ clustering, and that $\mathrm{NaCh}$ clustering may occur, followed by a redistribution of agrin within the $\mathrm{CHO}$ cell.

Agrin8-induced clusters of $\mathrm{NaChs}$ could occur anywhere on a muscle fiber. Figure $3 D$ shows an example of Agrin8-induced $\mathrm{NaCh}$ clustering near the end of a muscle fiber (bottom of the figure, $400 \mu \mathrm{m}$ from the endplate). We had originally predicted that we might be able to observe clustering only near the perijunctional region where $\mathrm{NaCh}$ density is greatest. This is clearly not the case, because we have observed clusters at distances $>600$ $\mu \mathrm{m}$ from the endplate (Fig. 4).

Figure 4 shows the distribution of clusters as a function of distance from the endplate. This is a summary of 70 positive contacts of 181 scorable contacts measured from four cultures. The data have been plotted as the percentage of scorable contacts that showed clusters. The number of contacts scored is shown above each bar. Notice that the percentage of contacts that caused clustering decreased beyond $80 \mu \mathrm{m}$. Using intensity measurements of the images, we determined that the average $\mathrm{NaCh}$ signal in the first $80 \mu \mathrm{m}$ from the endplate (excluding the signal from the endplate itself) was 2.5 times that of the background intensity measured at distances farther from the endplate. This is in agreement with loose patch-clamp measurements of sodium current density (Caldwell and Milton, 1988; Lupa et al., 1993). If the number of clusters at a given distance from the endplate is proportional to the density of $\mathrm{NaChs}$, there should be 2.5 times as many clusters in the first $80 \mu \mathrm{m}$ than in subsequent $80 \mu \mathrm{m}$ sections, and the sections $>80 \mu \mathrm{m}$ from the endplate should contain an equal number of clusters. We observed that the first 80 $\mu \mathrm{m}$ contained 1.7 times as many clusters as the average contained in the $80 \mu \mathrm{m}$ segments between 80 and $400 \mu \mathrm{m}$ from the endplate. This suggests that the probability of $\mathrm{NaChs}$ being clustered increases with the concentration of NaChs in the membrane but not in a linear manner. The number of contacts beyond $400 \mu \mathrm{m}$ decreased markedly, most likely because FDB fibers are $\sim 1 \mathrm{~mm}$ in length and the endplate usually is not in the exact middle of the fiber. This reduced the probability of finding contacts at distances $>400 \mu \mathrm{m}$, and the clusters observed at these greater distances, therefore, were not included in the average of the extrajunctional segments.

We did not observe clusters of $\mathrm{NaCh}$ in cocultures with wildtype CHO cells or the Agrin0-, Agrin11-, or Agrin19-transfected $\mathrm{CHO}$ cell lines. At least three separate experiments, each including twelve coverslips, were examined for the wild-type and for each transfected cell line; in each of these, $>100$ scorable contacts were observed with no $\mathrm{NaCh}$ clustering. Figure $3 E$ shows an example of an Agrin0-transfected $\mathrm{CHO}$ cell in contact with a muscle fiber. Even though this $\mathrm{CHO}$ cell was covering the endplate and the perijunctional area, there was no $\mathrm{CHO}$ cell-induced $\mathrm{NaCh}$ clustering.

\section{DISCUSSION}

During normal development, proper organization of the postsynaptic membrane at the NMJ is initiated by contact from the presynaptic terminal of a motor neuron. Neuronally expressed and secreted isoforms of agrin are known to be involved in the concentration of a variety of postsynaptic molecules at the NMJ (Wallace, 1989; McMahan, 1990). The purpose of this study was to determine whether any of the neuronally expressed isoforms of agrin could induce clustering of $\mathrm{NaChs}$ in dissociated adult muscle fibers and, therefore, perhaps be involved in the in vivo increased density of $\mathrm{NaChs}$ at the NMJ.

\section{Agrin-induced $\mathrm{NaCh}$ clustering}

We used a culture system that combined dissociated adult rat FDB muscle fibers and $\mathrm{CHO}$ cells that had been transfected with 

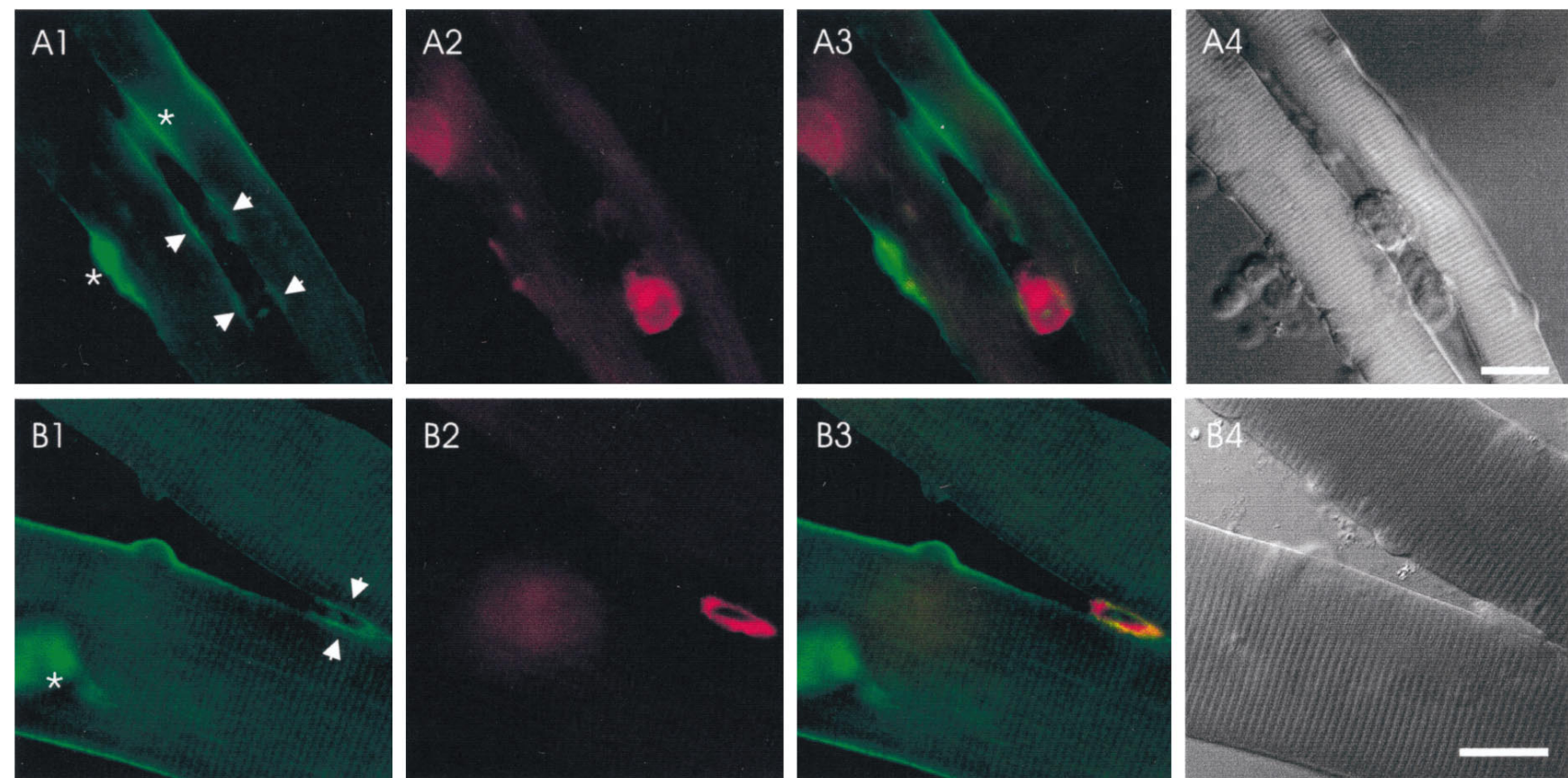

B2
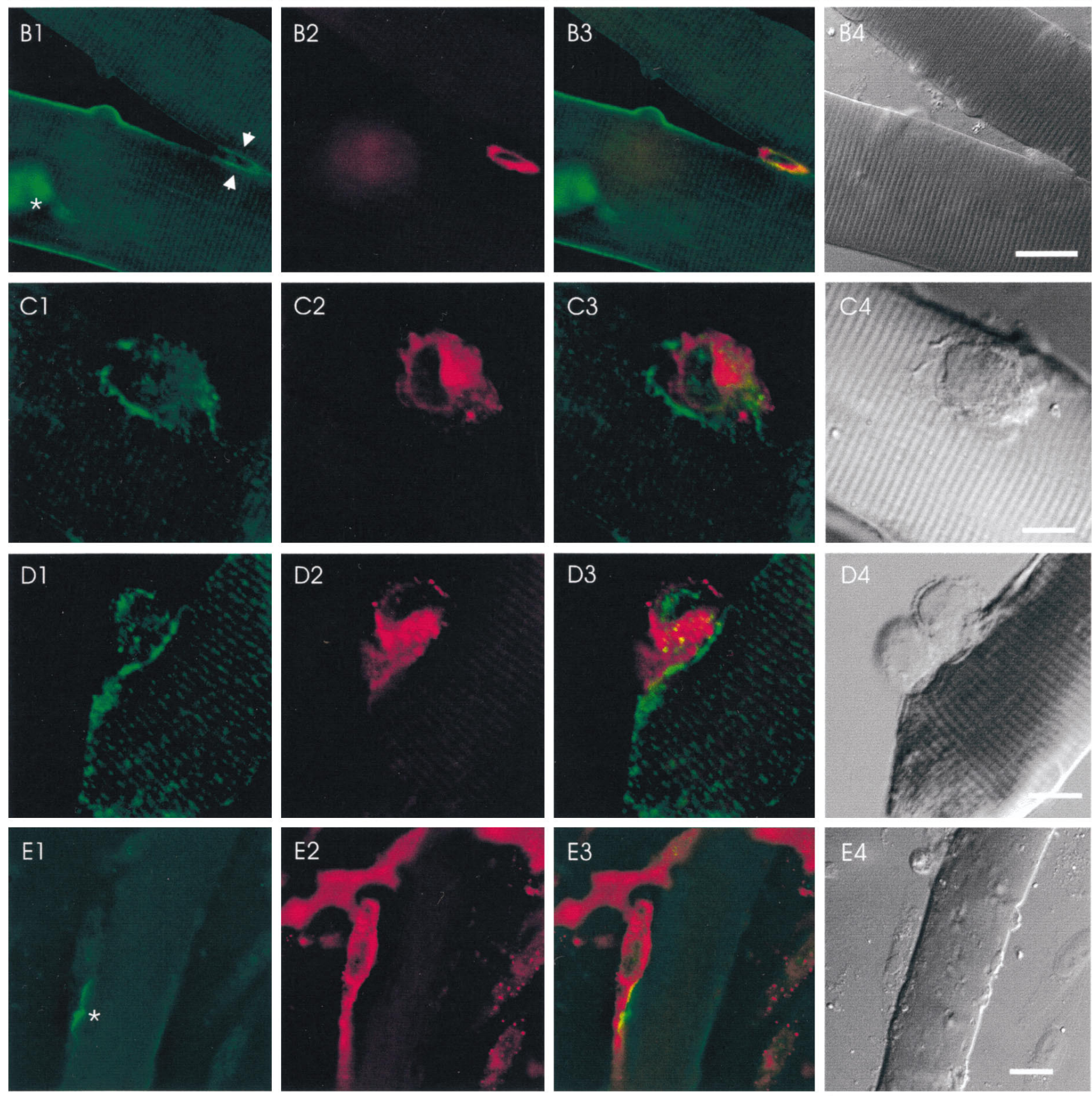


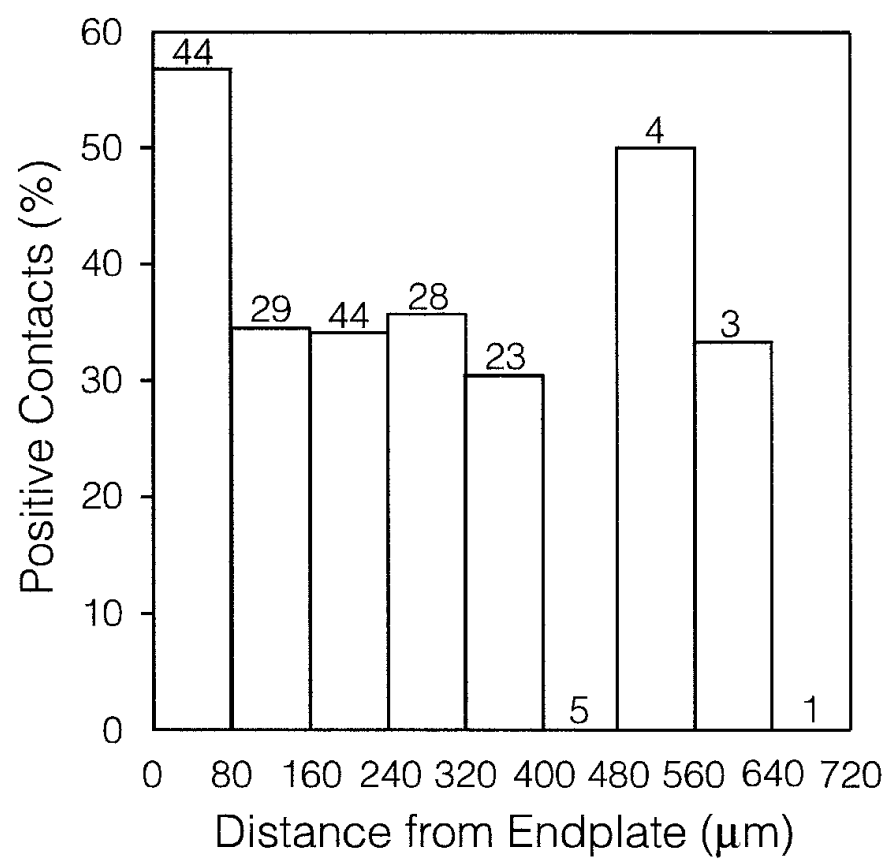

Figure 4. Distribution of Agrin8-induced NaCh clusters relative to the endplate of a muscle fiber. Data are the summary from four cultures. The vertical axis represents the percentage of contacts that induced clustering out of the scorable contacts observed (the number above each bar). The binwidth is $80 \mu \mathrm{m}$. Distance from the endplate was measured from the center of the endplate using an eyepiece reticule.

various isoforms of rat agrin. This system provided us with several advantages. The adult muscle fibers expressed a higher level of extrajunctional $\mathrm{NaChs}$ than embryonic myotubes. This allowed us to use an antibody against $\mathrm{NaCh}$ to assay for clustering rather than the more sensitive, yet spatially constrained, loose patchclamp technique. Using $\mathrm{CHO}$ cells that express agrin as a surface molecule may present a more physiological situation than bath application of soluble agrin, because it provides a focal presentation of agrin, as does a presynaptic nerve terminal.

We found that the Agrin8-transfected $\mathrm{CHO}$ cell line was able to cluster $\mathrm{NaChs}$ in cultured adult FDB fibers and that it was the only $\mathrm{CHO}$ cell line of the ones tested (one wild type and four transfected with different isoforms) that was able to do so. This is in contrast to clustering of AChRs, which occurs on myotubes in response to any of the splice variants containing an insert at the $\mathrm{z}$ site. Gesemann et al. (1995) measured the efficiency of the various isoforms in clustering AChRs and found that the 8-amino acid insert was the most effective. Limitations on measuring very low levels of $\mathrm{NaCh}$ density may have caused us to miss weak clustering produced by the other agrin isoforms. It is also possible that longer exposure to the agrin-transfected $\mathrm{CHO}$ cells would have revealed clustering by other agrin isoforms. Additionally, our in vitro assay system may not be an adequate model of the in vivo maturation of the NMJ. For example, differentiated adult muscle fibers may not respond to the same isoforms as muscle fibers from embryonic and neonatal animals. Ferns et al. (1993) found that membrane glycoproteins were necessary for the clustering of AChRs by some isoforms of agrin; adult FDB muscle fibers may lack receptors or glycoproteins specific for the other agrin isoforms.

A previous study (Lupa and Caldwell, 1991) showed that Torpedo agrin applied to the bath was unable to generate clusters of $\mathrm{NaChs}$ in adult FDB muscle fibers. Together with the results reported here, this suggests that unlike AChR aggregation, $\mathrm{NaCh}$ clustering may require agrin from the correct species, that Torpedo extract may not contain Agrin8, or that $\mathrm{NaCh}$ clustering may require focal application of agrin.

All of our analysis of $\mathrm{NaCh}$ clustering was done with light microscopy. Because light microscopy does not allow one to distinguish the $\mathrm{CHO}$ cell membrane from the muscle membrane at the site of contact, we cannot exclude the possibility that the $\mathrm{NaCh}$ signal originates in the $\mathrm{CHO}$ cell rather than in the muscle. We believe this explanation is unlikely, because the density of $\mathrm{NaChs}$ in $\mathrm{CHO}$ cell membranes is much lower than that in muscle cells and because, of the five $\mathrm{CHO}$ cell lines tested, only one was able to induce clustering. Moreover, we never observed $\mathrm{NaCh}$ clustering between pairs of Agrin8-expressing CHO cells. Thus, we interpret the increased $\mathrm{NaCh}$ signal at contact sites as coming from muscle membrane.

\section{Distribution of $\mathrm{NaCh}$ clustering}

Milton and Caldwell (1990) found that approximately half of the $\mathrm{NaChs}$ in extrajunctional regions of adult rodent FDB muscle fibers were free to diffuse within the membrane, and they proposed a model in which $\mathrm{NaChs}$ can attach and detach from binding sites during their lifetime in the membrane. We found that Agrin8-transfected $\mathrm{CHO}$ cells were more likely to induce $\mathrm{NaCh}$ clusters when they were close to the muscle fiber endplate.

Figure 3. CHO cells expressing Agrin8-induced $\mathrm{NaCh}$ clusters on muscle fibers after $1 \mathrm{~d}$ in culture $(A-D)$. Note that the images have been pseudocolored with the natural colors reversed. A1, NaCh labeling of two muscle fibers. The endplate on each fiber is indicated with an asterisk (endplate on top fiber is out of focus). Notice the $\mathrm{NaCh}$ clusters on the edge of both fibers (arrows). The endplate of the right fiber protruded into the space between the two fibers and produced an apparent $\mathrm{NaCh}$ signal on the left fiber that was considered to be an artifact. A2, Agrin labeling. Fluorescence in the top left corner is the result of detritus out of the focal plane. $A 3$, Composite image of $A 1$ and $A 2$. Notice that the NaCh clusters are coincident with the CHO cells (the top $\mathrm{CHO}$ cell contained agrin that was not in this plane of focus). A4, Nomarski image. The cluster of cells in the bottom left corner did not label for agrin (see $A 2$ ) and was not scored for clustering. B1, NaCh labeling of two muscle fibers with a $\mathrm{CHO}$ cell nestled at their juncture. Arrows show NaCh clustering at the $\mathrm{CHO}$ cell contact. Asterisk indicates out-of-focus endplate. Notice the myonucleus bulging from the bottom fiber in the perijunctional region. $B 2$, Agrin labeling. B3, Composite image of $B 1$ and B2. B4, Nomarski image. $C, \mathrm{NaCh}$ clustering induced by an Agrin8-expressing CHO cell on top of a muscle fiber (110 $\mu \mathrm{m}$ from endplate). $C 1, \mathrm{NaCh}$ labeling. $C 2$, Agrin labeling. $C 3$, Composite image of $C 1$ and $C 2$. $C 4$, Nomarski image. The NaCh labeling was coincident with the thin, flat contact between $\mathrm{CHO}$ cell and muscle fiber. $D$, NaCh clustering induced by two Agrin8-expressing CHO cells near the end of a muscle fiber ( $400 \mu \mathrm{m}$ from endplate). $\mathrm{D1}, \mathrm{NaCh}$ labeling. The $\mathrm{NaCh}$ signal from the $\mathrm{CHO}$ cell was one of the strongest seen; a more typical example is illustrated in E1.D2, Agrin labeling. D3, Composite image of D1 and D2. Both CHO cells contained agrin, but the agrin signal in one cell was not in this focal plane. Notice that there is NaCh labeling on the fiber adjacent to both cells. D4, Nomarski image. E, Agrin0-transfected CHO cells do not induce $\mathrm{NaCh}$ clustering. This example was chosen because the contact is close to the endplate where channel density is highest and where the highest incidence of clusters occurred with Agrin8 cells (Fig. 4). E1, NaCh labeling. Notice the labeling of the endplate (asterisk) and the perijunctional region directly across from the endplate. E2, Agrin labeling. The amorphous signals in the top portion of the panel are from CHO cells out of the plane of focus. E3, Composite of $E 1$ and $E 2$. The $\mathrm{CHO}$ cell next to the endplate is not able to cluster NaChs, even though it is directly adjacent to the endplate. E4, Nomarski image. Scale bars: $A, B, E, 20 \mu \mathrm{m} ; C, D, 10 \mu \mathrm{m}$. 


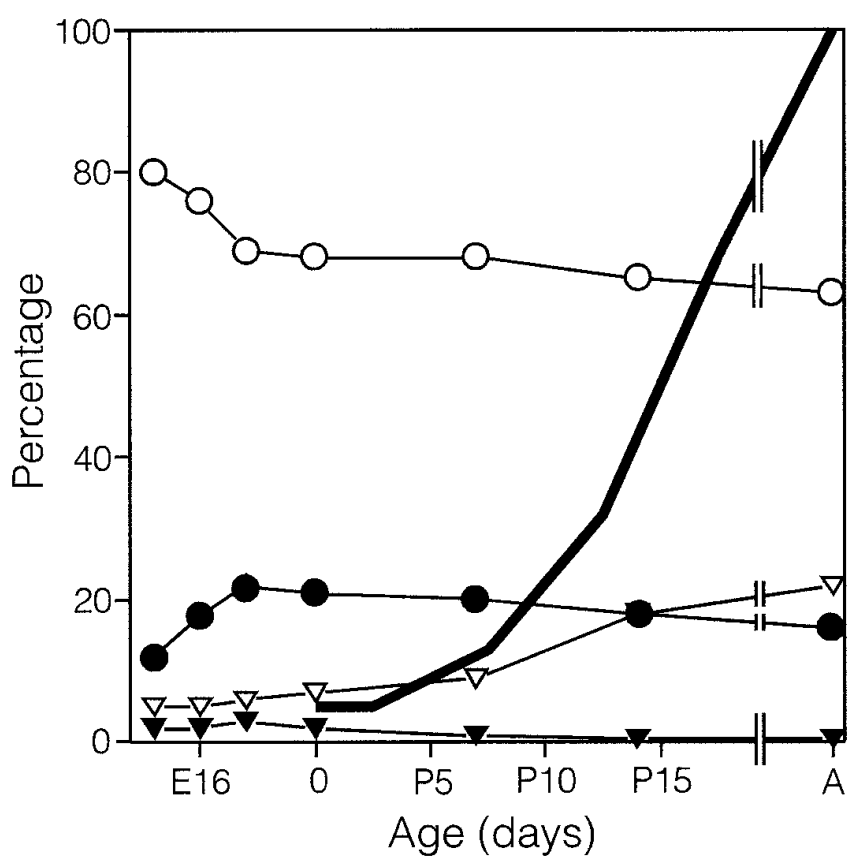

Figure 5. Comparison of the developmental time course of $\mathrm{NaCh}$ aggregation at the endplate in postnatal rat muscle with pre- and postnatal expression of agrin RNA variants in rat spinal cord. Amino acid inserts at the $\mathrm{z}$ site are represented as follows: no insert, open circles; 8 amino acids, open triangles; 11 amino acids, solid triangles; 19 amino acids, solid circles. Data are replotted from Hoch et al. (1993) and are expressed as the percentage of total agrin. The solid line without symbols represents the enhancement of junctional $\mathrm{NaCh}$ current over extrajunctional current relative to adult enhancement; $100 \times$ (junctional current - extrajunctional current)/(adult junctional current - adult extrajunctional current). Data are replotted from Lupa et al. (1993).

Because the concentration of $\mathrm{NaCh}$ increases with proximity to the endplate, it raises the possibility that the Agrin8-transfected $\mathrm{CHO}$ cells have access to more $\mathrm{NaCh}$ closer to the endplate and that this increases the likelihood of clustering close to the endplate. This is based on the assumption that new clusters of $\mathrm{NaChs}$ are formed from $\mathrm{NaChs}$ that are not permanently anchored to the cytoskeleton, as has been suggested for AChRs (Wallace, 1992).

Only approximately one-third of the Agrin8 CHO cell-muscle contacts produced clusters of $\mathrm{NaChs}$, which is similar to the percentage of Agrin8 CHO cell contacts that induced AChRs (Campanelli et al., 1991). This low fraction could be attributable to a variable amount of time that the $\mathrm{CHO}$ cells contacted the fiber; however, when we observed identified $\mathrm{CHO}$ cells in the same culture over a 4-6 hr period, there were small changes in position but little evidence for significant migration. Alternatively, the density of the membrane receptor for agrin may be limiting. $\alpha$-Dystroglycan is a receptor for agrin (Bowe et al., 1994; Campanelli et al., 1994; Gee et al., 1994; Sugiyama et al., 1994), but there is evidence that another receptor exists that mediates agrin-induced AChR clustering (Gesemann et al., 1996; Meier et al., 1996); the identity and membrane density of this receptor are unknown.

\section{Developmental regulation of $\mathrm{NaCh}$ clustering}

During development, neuronal expression of Agrin8 increases markedly starting 1 week after birth; expression of other isoforms either changes very little or decreases (Hoch et al., 1993, their Figs. 6, 7). This increase in Agrin8 expression corresponds closely with the expression and concentration of the adult subtype of $\mathrm{NaCh}$ at the NMJ (Lupa et al., 1993, their Fig. 2). Figure 5 shows a plot of the contribution of various $\mathrm{z}$ site splice variants to the total agrin in the spinal cord at different developmental stages (RNA levels replotted from Hoch et al., 1993). Notice that the relative expression of Agrin8 corresponds temporally to the increase in junctional $\mathrm{NaCh}$ concentration (solid line with no symbols, redrawn from Lupa et al., 1993). This temporal relationship, in conjunction with our findings here, suggests that the onset of Agrin8 expression is responsible for clustering of $\mathrm{NaChs}$ at the NMJ during normal development.

The expression and concentration of the adult $\mathrm{NaCh}$ subtype at the NMJ begin shortly after birth as the muscle shifts expression of $\mathrm{NaCh}$ subtype from the embryonic form (identical to the cardiac subtype rH1 that is also designated SkM2 or $\mu 2$ ) to the adult form (SkM1). Although this switch coincides with the development of the high $\mathrm{NaCh}$ density at the endplate, both subtypes can be concentrated at the endplate (Caldwell and Milton, 1988; Lupa et al., 1995). The aggregation at the developing endplate coincides temporally with other late synaptic formation events such as infolding of the postsynaptic membrane and the appearance of a specific isoform of protein kinase $\mathrm{C}$ ( $\mathrm{PKC} \theta)$ (Hilgenberg and Miles, 1995). It is possible that Agrin8 is also responsible for induction of folds and the localization of PKC $\theta$.

\section{Related mechanisms of molecular aggregation}

Because NaChs and AChRs are not precisely co-localized and because they become concentrated at different developmental stages, it follows that some of the mechanisms and molecules controlling expression and localization of these proteins are different. In addition to agrin, other molecules released by the nerve terminal might be involved in $\mathrm{NaCh}$ clustering. Neuregulin is a signaling molecule that is synthesized by motor neurons and deposited in the synaptic basal lamina (Jo et al., 1995). Multiple transcripts for neuregulin are generated by alternative splicing, and some of these isoforms can increase AChR synthesis and the density of NaChs on the surface of cultured muscle cells (for review, see Mudge, 1993). Receptors for neuregulin are members of the EGF receptor family and are protein tyrosine kinases. Three members of this family (erbB2, erbB3, and erbB4) are concentrated at the NMJ of adult skeletal muscle. Expression of neuregulin and its receptors increases during early postnatal development (Zhu et al., 1995). The similarity in developmental appearance of $\mathrm{NaChs}$ and neuregulin/erbBs suggests that in addition to agrin, some isoforms of neuregulin may regulate $\mathrm{NaCh}$ density at the endplate.

Intracellular molecules establish or maintain the specialized membrane at the endplate. Because $\mathrm{NaChs}$ and AChRs are in separate domains in the subsynaptic membrane (Flucher and Daniels, 1989), the molecules that link NaChs to the cytoskeleton are likely to be different from those that tether AChRs. Ankyrin, which co-purifies with NaChs (Srinivasan et al., 1988), is a candidate for immobilizing NaChs. Three genes for ankyrin have been identified, and multiple isoforms are generated by alternative splicing; the specific isoform(s) present at the NMJ has not been determined.

Other membrane-associated, intracellular molecules that could tether $\mathrm{NaChs}$ are those that contain PDZ binding domains. The PDZ domain consists of $\sim 90$ amino acids and is present in several homologous proteins (Cho et al., 1992). Candidate molecules with a PDZ domain are the syntrophins, a family of proteins that bind to dystrophin and are part of the dystrophin-glycoprotein complex (Adams et al., 1995; Yang et al., 1995). One of the syntro- 
phins is concentrated at the NMJ (Peters et al., 1994) and could participate in tethering $\mathrm{NaChs}$.

\section{Conclusion}

The coculture experiments presented here show that a specific neural isoform of agrin (Agrin8) is capable of rapidly clustering $\mathrm{NaChs}$. This is the one isoform for which temporal expression during development coincides with the postnatal aggregation of $\mathrm{NaChs}$ at the endplate and other late processes of synapse maturation. These results support the hypothesis that Agrin8 is a common signal that initiates not only $\mathrm{AChR}$ and $\mathrm{NaCh}$ clustering but also additional postsynaptic specializations required for synapse formation and maturation.

\section{REFERENCES}

Adams ME, Dwyer TM, Dowler LL, White RA, Froehner SC (1995) Mouse $\alpha 1$ - and $\beta 2$-syntrophin gene structure, chromosome localization, and homology with a discs large domain. J Biol Chem 270:25859-25865.

Apel ED, Merlie JP (1995) Assembly of the postsynaptic apparatus. Curr Opin Neurobiol 5:62-67.

Bekoff A, Betz WJ (1977) Physiological properties of dissociated muscle fibres obtained from innervated and denervated adult rat muscle. J Physiol (Lond) 271:25-40.

Betz W, Sakmann B (1973) Effects of proteolytic enzymes on function and structure of frog neuromuscular junctions. J Physiol (Lond) 230:673-688.

Bowe MA, Deyst KA, Leszyk JD, Fallon JR (1994) Identification and purification of an agrin receptor from Torpedo postsynaptic membranes: a heteromeric complex related to the dystroglycans. Neuron 12:1173-1180.

Burden SJ, Sargent PB, McMahan UJ (1979) Acetylcholine receptors in regenerating muscle accumulate at original synaptic sites in the absence of the nerve. J Cell Biol 82:412-425.

Caldwell JH, Milton RL (1988) Sodium channel distribution in normal and denervated rodent and snake skeletal muscle. J Physiol (Lond) 401:145-161.

Caldwell JH, Campbell DT, Beam KG (1986) Na channel distribution in vertebrate skeletal muscle. J Gen Physiol 87:907-932.

Campanelli JT, Hoch W, Rupp F, Kreiner T, Scheller RH (1991) Agrin mediates cell contact-induced acetylcholine receptor clustering. Cell 67:909-916.

Campanelli JT, Roberds SL, Campbell KP, Scheller RH (1994) A role for dystrophin-associated glycoproteins and utrophin in agrin-induced AChR clustering. Cell 77:663-674.

Cho K-O, Hunt CA, Kennedy MB (1992) The rat brain postsynaptic density fraction contains a homolog of the Drosophila discs-large tumor suppressor protein. Neuron 9:929-942.

Dugandzija-Novakovic S, Koszowski AG, Levinson SR, Shrager P (1995) Clustering of $\mathrm{Na}^{+}$channels and node of Ranvier formation in remyelinating axons. J Neurosci 15:492-503.

Ferns M, Hoch W, Campanelli JT, Rupp F, Hall ZW, Scheller RH (1992) RNA splicing regulates agrin-mediated acetylcholine receptor clustering activity on cultured myotubes. Neuron 8:1079-1086.

Ferns MJ, Campanelli JT, Hoch W, Scheller RH, Hall Z (1993) The ability of agrin to cluster AChRs depends on alternative splicing and on surface proteoglycans. Neuron 11:491-502.

Flucher BE, Daniels MP (1989) Distribution of $\mathrm{Na}^{+}$channels and ankyrin in neuromuscular junctions is complementary to that of acetycholine receptors and the $43 \mathrm{kDa}$ protein. Neuron 3:163-175.

Froehner SC (1991) The submembrane machinery for nicotinic acetylcholine receptor clustering. J Cell Biol 114:1-7.

Gee SH, Montanaro F, Lindenbaum MH, Carbonetto S (1994) Dystroglycan-alpha, a dystrophin-associated glycoprotein, is a functional agrin receptor. Cell 77:675-686.

Gesemann M, Denzer AJ, Ruegg MA (1995) Acetylcholine receptoraggregating activity of agrin isoforms and mapping of the active site. $\mathrm{J}$ Cell Biol 128:625-636.

Gesemann M, Cavalli V, Denzer AJ, Brancaccio A, Schumacher B, Ruegg MA (1996) Alternative splicing of agrin alters its binding to heparin, dystroglycan and the putative agrin receptor. Neuron 16:755-767.
Hilgenberg L, Miles K (1995) Developmental regulation of a protein kinase $\mathrm{C}$ isoform localized in the neuromuscular junction. J Cell Sci 108:51-61.

Hoch W, Ferns M, Campanelli JT, Hall ZW, Scheller RH (1993) Developmental regulation of highly active alternatively spliced forms of agrin. Neuron 11:479-490.

Hoch W, Campanelli JT, Harrison S, Scheller RH (1994) Structural domains of agrin required for clustering of nicotinic acetylcholine receptors. EMBO J 13:2814-2821.

Jo SA, Zhu X, Marchionni MA, Burden SJ (1995) Neuregulins are concentrated at nerve-muscle synapses and activate ACh-receptor gene expression. Nature 373:158-161.

Lalik PH, Krafte DS, Volberg WA, Ciccarelli RB (1993) Characterization of endogenous sodium channel gene expressed in chinese hamster ovary cells. Am J Physiol 264:C803-C809.

Lupa MT, Caldwell JH (1991) Effect of agrin on the distribution of acetylcholine receptors and sodium channels on adult skeletal muscle fibers in culture. J Cell Biol 115:765-778.

Lupa MT, Caldwell JH (1994) Sodium channels aggregate at former synaptic sites in innervated and denervated regenerating muscles. J Cell Biol 19:139-147.

Lupa MT, Krzemien DM, Schaller KL, Caldwell JH (1993) Aggregation of sodium channels during development and maturation of the neuromuscular junction. J Neurosci 13:1326-1336.

Lupa MT, Krzemien DM, Schaller KL, Caldwell JH (1995) Expression and distribution of sodium channels in short- and long-term denervated rodent skeletal muscles. J Physiol (Lond) 483.1:109-118.

McMahan UJ (1990) The agrin hypothesis. Cold Spring Harb Symp Quant Biol 50:407-418.

McMahan UJ, Horton SE, Werle MJ, Honig LS, Kröger S, Ruegg MA, Escher G (1992) Agrin isoforms and their role in synaptogenesis. Curr Opin Cell Biol 4:869-874.

Meier T, Gesemann M, Cavalli V, Ruegg MA, Wallace BG (1996) AChR phosphorylation and aggregation induced by an agrin fragment that lacks the binding domain for $\alpha$-dystroglycan. EMBO J 15:2625-2631.

Milton RL, Caldwell JH (1990) Na current in membrane blebs: implications for channel mobility and patch clamp recording. J Neurosci 10:885-893.

Mudge AW (1993) New ligands for neu? Curr Biol 3:361-364.

Nastuk MA, Fallon JR (1993) Agrin and the molecular choreography of synapse formation. Trends Neurosci 16:72-76.

Peters MF, Kramarcy NR, Sealock R, Froehner SC (1994) NeuroReport 5:1577-1580.

Ruegg MA, Tsim KWK, Horton SE, Kroger S, Escher G, Gensch EM, McMahan UJ (1992) The agrin gene codes for a family of basal lamina proteins that differ in function and distribution. Neuron 8:691-699.

Rupp F, Payan DG, Magill-Solc C, Cowan DM, Scheller RH (1991) Structure and expression of rat agrin. Neuron 6:811-823.

Rupp F, Ozcelik TH, Linial M, Peterson K, Francke U, Scheller R (1992) Structure and chromosomal localization of the mammalian agrin gene. J Neurosci 12:3535-3544.

Srinivasan Y, Elmer L, Davis J, Bennett V, Angelides K (1988) Ankyrin and spectrin associate with voltage-dependent sodium channels in brain. Nature 333:177-180.

Sugiyama J, Bowen DC, Hall ZW (1994) Dystroglycan binds nerve and muscle agrin. Neuron 13:103-115.

Thomas WS, O'Dowd DK, Smith MA (1993) Developmental expression and alternative splicing of chick agrin RNA. Dev Biol 158:523-535.

Wallace BG (1989) Agrin-induced specializations contain cytoplasmic, membrane, and extracellular matrix-associated components of the postsynaptic apparatus. J Neurosci 9:1294-1302.

Wallace BG (1992) Mechanism of agrin-induced acetylcholine receptor aggregation. J Neurobiol 23:592-604.

Yang B, Jung D, Rafael JA, Chamberlain JS, Campbell KP (1995) Identification of $\alpha$-syntrophin binding to syntrophin triplet, dystrophin, and utrophin. J Biol Chem 270:4975-4978.

Zhu X, Lai C, Thomas S, Burden SJ (1995) Neuregulin receptors, erbB3 and erbB4, are localized at neuromuscular synapses. EMBO J 14:5842-5848. 